\title{
Tamarind Multifunctional Protein: Safety and Anti-Inflammatory Potential in Intestinal Mucosa and Adipose Tissue in a Preclinical Model of Diet-Induced Obesity
}

\author{
Vanessa C.O. Lima ${ }^{a}$ Anna B.S. Luz ${ }^{a}$ Maria do Socorro M. Amarante ${ }^{b}$ \\ Maíra C.J.S. Lima ${ }^{c}$ Fabiana M.C. Carvalho ${ }^{a}$ Julia B.S. Figueredo ${ }^{a}$ \\ Pedro P.A. Santos ${ }^{b}$ Christina S. Camillo ${ }^{b}$ Fernando V.L. Ladd ${ }^{b}$ \\ Bruna L.L. Maciel $^{d}$ Adriana F. Uchôa ${ }^{a}$ e Ana H.A. Morais ${ }^{a}$ d \\ aBiochemistry Postgraduate Program, Biosciences Center, Federal University of Rio Grande do Norte, Natal, Brazil; \\ ${ }^{b}$ Morphology Department, Biosciences Center, Federal University of Rio Grande do Norte, Natal, Brazil; 'Veterinary \\ course, Potiguar University, Natal, Brazil; dNutrition Postgraduate Program, Center for Health Sciences, Federal \\ University of Rio Grande do Norte, Natal, Brazil; 'Proteome Laboratory, Institute of Tropical Medicine, Federal \\ University of Rio Grande do Norte, Natal, Brazil
}

\section{Keywords}

Obesity · Trypsin inhibitor · Intestine · Toxicity · Visceral fat · Imflammation

\begin{abstract}
Introduction: Obesity has emerged as one of the main public health problems. This condition triggers a series of hormonal and metabolic changes related to a low-grade chronic inflammatory condition. The trypsin inhibitor purified from tamarind (TTIp) seeds is a promising anti-inflammatory molecule, but its safety needs to be evaluated. This study aimed to evaluate TTIp bioactive dose effects on organs involved in its metabolism (liver and pancreas) and affected tissues (small intestine and perirenal adipose tissue) in an obesity model. Methods: Three groups of adult male Wistar rats were used $(n=5)$. Two of these groups had diet-induced obesity, and a third group was eutrophic. TTIp was administered by gavage in one of the obese groups for 10 days, while the remaining groups received a vehicle. The chromato-
\end{abstract}

karger@karger.com www.karger.com/ofa

Karger $\stackrel{\text { ' }}{5}$

BOPEN ACCESS
(C) 2021 The Author(s)

Published by S. Karger AG, Basel

This is an Open Access article licensed under the Creative Commons Attribution-NonCommercial-4.0 International License (CC BY-NC) (http://www.karger.com/Services/OpenAccessLicense), applicable to the online version of the article only. Usage and distribution for commercial purposes requires written permission. graphic profile and the inhibition assay corroded the purification of the inhibitor. Physical and behavioral changes, liver enzymes, and stereological and histopathological analyses of tissues were evaluated. Results: TTlp did not cause visible signs of toxicity, nor caused changes in liver enzymes, the liver, and pancreatic tissues. TTlp did not cause changes in the intestinal mucosa, showing improvement in the villi's histopathological characteristics compared to the group of animals with obesity without treatment with TTlp $(p=0.004)$. The analysis of perirenal adipose tissue showed that the average sectional area of animals with obesity that received TTIp did not differ from the control. There was a difference between the high glycemic load diet group and the group treated with the inhibitor $(351.8 \pm 55.5)(p=0.016)$. In addition, the group that received TTIp had no inflammatory infiltrates. Conclusion: Based on histological and stereological analysis, the use of TTlp is potentially safe and anti-inflammatory in the evaluated obesity model and can be investigated as a possible adjuvant in obesity therapy.

(c) 2021 The Author(s).

Published by S. Karger AG, Basel

Correspondence to:

Ana H.A. Morais, aharaujomorais@gmail.com 


\section{Introduction}

Obesity is one of the main global epidemics of the 21st century. Approximately 1.9 billion adults are overweight. Of these, 650 million have obesity, according to the body mass index (BMI) [1]. Lifestyle changes, which mainly involve adopting healthy eating habits, the practice of physical activity, and the abstention from tobacco use, have a high degree of recommendation within the measures of coping with overweight/obesity. However, these measures have not had an expected effect on the dizzying growth of these morbidities [2].

When lifestyle change measures fail, or other diseases are associated with obesity, adjuvant pharmacotherapeutic treatment is recommended. The individual response to weight loss due to medication use can be variable, and its adverse effects anticipate the need for therapy interruption [3].

The search for new treatment alternatives for obesity has become an urgent need, and with this, new molecules with promising roles have emerged. In this field, trypsin inhibitors, protein molecules extracted mainly from plant sources, with a range of pharmacological effects [4-7], have gained prominence. Among these molecules, the trypsin inhibitor extracted from tamarind seeds (Tamarindus indica L.) has been reported in experimental models of obesity [8].

Initial studies with tamarind trypsin inhibitors (TTIs) showed that when isolated, TTI was able to reduce food consumption in an animal model and stimulate the secretion of cholecystokinin, a hormone with satietogenic properties [9]. When obesity was induced in an experimental model, TTI, despite not leading to weight loss, reduced food consumption, plasma concentrations of the inflammatory cytokine TNF- $\alpha$ [10], and the expression of the $C C K-1 R$ gene and plasma leptin in obese Wistar rats [11]. However, a protein isolate can contain diverse proteins, and its purification was performed to analyze the trypsin inhibitor's action more precisely [12].

The trypsin inhibitor purified from tamarind (TTIp) continued to reduce plasma leptin in Wistar rats with obesity. However, as already noted by Costa et al. [11], it did not affect plasma CCK in these same animals [12]. Animals treated with TTIp also presented less TNF- $\alpha$ immunostaining in adipocytes and fewer plasma concentrations of this cytokine than non-treated animals [13]. These results showed this molecule's potential because obesity is classically considered a disease that induces low-grade chronic inflammation, causing changes in im- portant tissues, notably the intestinal mucosa [14] and tissue [15].

Due to these promising biological effects of TTIp in alternative obesity therapy, the safety of the bioactive dose $(750 \mu \mathrm{g} / \mathrm{kg})[12,13]$ and its use need to be evaluated. Trypsin inhibitors have deleterious effects well reported in the literature. Its administration in animal models resulted in an impaired growth rate due to malabsorption, digestion and use of nutrients, mainly amino acids, and metabolic changes in the pancreas, such as increased enzyme secretion, hypertrophy, and hyperplasia [16]. Due to the administration of TTIp (via gavage), the gastrointestinal tract organs, classically affected by the action of this trypsin inhibitor, may be susceptible to a toxicity process, as well as the adipose tissue, which is an important biological target. Thus, this study aimed to assess the TTIp bioactive dose for possible toxic effects, focusing on the histopathological and stereological analysis of organs involved in its metabolism, processing and biological activity (liver and pancreas), and the tissues most affected in an obesity model (small intestine and visceral adipose tissue).

\section{Materials and Methods}

Animals

Adult male Wistar rats, with an average weight of $372 \mathrm{~g} \pm$ $12.9 \mathrm{~g}(n=5)$, and adult male Wistar rats with diet-induced obesity for 17 weeks [17], with an average weight of $400 \mathrm{~g} \pm 27 \mathrm{~g}(n=$ $10)$, were kept in individual cages. Water and diet were offered ad libitum, maintaining light conditions ( $12 \mathrm{~h}$ light/dark cycle), with an average temperature of $22^{\circ} \mathrm{C}$ and controlled humidity $(50 \pm$ $5 \%)$. All experiments were developed according to the Guide for the Care and Use of Laboratory Animals (2011) and approved by the Ethics Committee on the Use of Animals (CEUA-UnP), protocol No. 012/2015.

Diets

The diets used in the experiment were the standard Labina ${ }^{\circledR}$ diet (Paulínia, São Paulo, Brazil) and the high glycemic index (77.6) and high glycemic load (HGLI) (38.8) diet. The HGLI diet consisted of $315 \mathrm{kcal}, 21 \%$ protein, $4 \%$ lipids, and $48 \%$ carbohydrates [17] and was produced at the Laboratory of Dietetic Technique of the Federal University of Rio Grande do Norte-UFRN (Natal, Rio Grande do Norte, Brazil).

\section{Obtaining TTIP}

TTIp was obtained according to the methodology described by Medeiros et al. [12]. Briefly, the purification was performed using high-precision liquid chromatography with reverse phase column (Hilicon AB, Umea, Sweden), using liquid chromatograph LC$10 \mathrm{~A}$ composed of a binary solvent pumping system (Shimadzu Corporation, Kyoto, Japan) coupled to UV-Vis spectrophotometer (SDP-10A VP) (Mettler-Toledo Ind. e Com. Ltda., Barueri, São 
Paulo), Rheodyne injector, and workstation with system control application (SCL-10Avp system controller). Vydac C18 218TP54 analytical column (Hichrom, Berkshire, England), $5 \mu \mathrm{m}, 4.6 \times 250$ $\mathrm{mm}, 300 \AA$ was used. Solvent A was analytical grade water and $0.1 \%$ TFA and solvent $B$, acetonitrile and $0.1 \%$ trifluoroacetic acid. The elution of the protein of interest was monitored by UV detection at $216 \mathrm{~nm}$ and $280 \mathrm{~nm}$ wavelengths. The collections were carried out manually and the peak of interest, called TTIp, was subjected to an inhibition test for trypsin to conform the anti-triptych activity [18].

Experimental Design

The animals were divided into 3 groups $(n=5)$ and submitted to 10 days of treatment with TTIp $(730 \mu \mathrm{g} / \mathrm{kg})$ by gavage or the vehicle (distilled water) by gavage. The experiment's time and the TTIp concentration were the same as in other studies, where TTIp showed biological activity $[12,13]$. The groups were as follows (1) control group: eutrophic animals, fed with a standard balanced diet for the species, and receiving vehicle for gavage (2) HGLI diet group: animals with obesity, fed the HGLI diet, and receiving vehicles by gavage; and (3) TTIp group: animals with obesity, fed the HGLI diet, and receiving TTIp by gavage. Both diets and water for hydration were offered ad libitum during the days of experimentation.

The animals were evaluated daily for signs of general toxicity (locomotor and behavioral changes such as apathy, increased/decreased touch response, constipation, diarrhea, piloerection check, hair loss, and death). At the end of the experiment, the animals fasted for $8 \mathrm{~h}$ and were then anesthetized with $250 \mathrm{mg}$ of tiletamine hydrochloride and $250 \mathrm{mg}$ of zolazepam hydrochloride. The blood was removed from the hepatic portal vein and centrifuged. The serum was used to measure liver transaminases and gamma-glutamyl transpeptidase enzyme-colorimetric method (Kit CELM ${ }^{\circledR}$, São Paulo, Brazil). The animals were then euthanized in a $\mathrm{CO}_{2}$ chamber, and the small intestine (jejunum), perirenal visceral adipose tissue, liver, and pancreas were collected for elaboration of histological slides and further analysis.

\section{Elaboration and Image Capture of Histological Slides}

Tissue fragments were fixed for $24 \mathrm{~h}$ in $10 \%$ buffered formalin for histopathological analysis. After fixation, the material was dehydrated in an increasing alcoholic series, diaphanized in xylol, impregnated, and embedded in paraffin. The tissue sections (3-4 $\mu \mathrm{m})$ were stained with hematoxylin and eosin. The slide images were captured using a DS-Ri1 digital camera (Nikon, Edgewood, NY, USA) coupled to an Eclipse Ni microscope (Nikon, Edgewood, NY, USA) $(\times 10)$ with the aid of the Nis-Elements AR 64 bits software (Nikon).

\section{Histopathological Analyses}

Histological slides of perirenal adipose tissue and slides of the liver, pancreas and small intestine were analyzed by a blind phatologist for the presence of alterations indicative of damage, with an Eclipse Ni microscope (Nikon, Edgewood, NY, USA) with $\times 10$ objective. For analysis of the intestinal blades and perirenal adipose tissue, semiquantitative analysis was performed that scored the specific parameters for each tissue.

For the intestine, the percentage of intact villi, ulcerated villi, absence of villi, villus necrosis, and intestinal glands' integrity were evaluated. For perirenal adipose tissue, the percentages of unilocular adipocytes, multilocular adipocytes, and lipolysis were evaluated.

Safety and Anti-Inflammatory Effect of Tamarind Multifunctional Protein
Adapting the methodology by Silva et al. [19], a score was assigned to define the percentages as follows: if the characteristic was absent, a score of 0 (zero) was assigned; if $0-25 \%$, a score of 1 was assigned; if $25-50 \%$, a score of 2 was assigned; if $50-75 \%$, a score of 3 was assigned; and if $>75 \%$, a score of 4 was assigned. A score was assigned according to the number of foci found to assess inflammatory infiltrate foci in adipose tissue: 0 for the absence of foci; 1 for $1-3$ foci; 2 for $4-6$ foci; and 3 for $>6$ foci [20]. For adipose tissue fibrosis, 0 was assigned for absence and 1 for the presence of this finding [21]. Additionally, the compliance of intestinal villi (px) and the number of goblet cells were evaluated.

\section{Stereological Analysis of the Slides}

Stereological analysis was performed based on the capture of 5 images of random sections of each histological slide. Investigation of the volume density $\left(V_{\mathrm{v}}\right)$ and total adipocyte volume ( $V_{\text {TOTADIP }}$ ) present in the perirenal visceral adipose tissue was performed, adapting the equations proposed by Ribeiro et al. [22]. The medium sectional area was acquired, according to Bargut et al. [23]. For the estimation of $V_{\mathrm{v}}$, a test system was superimposed on the reference space. The total number of points on the region of interest (cells) (Pint) and the total number of points on the reference space (Pref) were counted. The following equation was used:

$$
V_{\mathrm{v}}=\sum \text { Pint } \div \sum \text { Pref. }
$$

$V_{\mathrm{v}}$ ranges from 0 to 1 but can be expressed as a percentage [22].

The cell medium sectional area was obtained through the relationship between $V_{\mathrm{v}}$ and twice the numerical density per area of adipocytes (QA), which was estimated as the number of adipocytes counted in a frame and the test area of the frame [23], according to the following equation:

$\mathrm{MSA}=V_{\mathrm{v}} \div 2 \times$ QA.

The QA is obtained by the ratio between the number of adipocytes and the area of the frame.

\section{Statistical Analysis}

The sample size was calculated according to the variation coefficient (10\%), and the difference between the treatments was considered significant $(25 \%)$, with an error probability of $<5 \%(p<$ 0.05 ) and power of $90 \%$. The ANOVA parametric test and the Tukey post-test were used to analyze continuous variables to compare groups. For the bowel slides' semiquantitative analysis, the Kruskal-Wallis nonparametric test and Dunn's test were used to assess differences between groups. The Kruskal-Wallis nonparametric test was also used to analyze liver enzymes' biochemical measurements with post hoc Dunn's test. The data were analyzed using the IBM $^{\circledR}$ SPSS $^{\circledR}$ Statistics 22.0 program (Armonk, NY, USA). GraphPad Prism 5.0 software (La Jolla, CA, USA) was used to plot the graphs.

\section{Results}

\section{Obtaining TTIP}

Figure 1 shows the chromatographic profile of TTIp. The first peak before $5 \mathrm{~min}$ corresponds to the salt elution. TTIp is the second major peak (signaled in Fig. 1). 


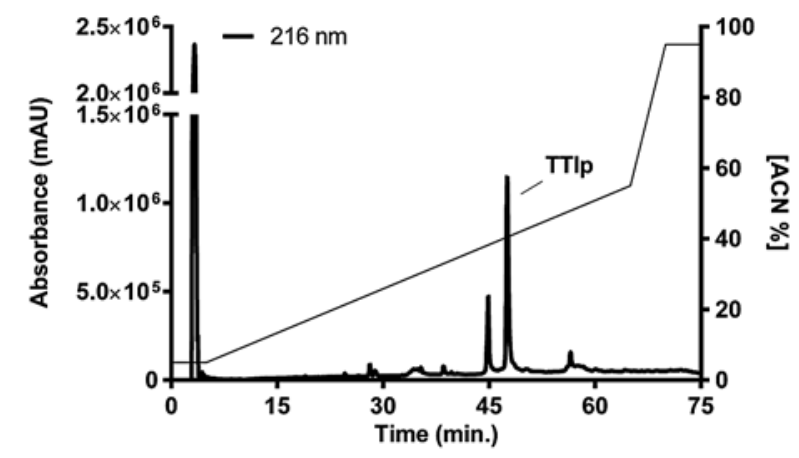

Fig. 1. Chromatographic profile of TTIp in high-performance liquid chromatography of reverse phase in analytical column C18 Vydac. The peak was obtained with an acetonitrile gradient and elution was monitored at $215 \mathrm{~nm}$ and $280 \mathrm{~nm}$ wavelengths. The first peak before $15 \mathrm{~min}$ corresponds to salt elution. The TTIp peak is shown in the figure. TTIp, trypsin inhibitor purified from tamarind.

The peak that preceding TTIp was also visualized by Medeiros et al. [12] and most likely corresponds to the purified inhibitor, but in another isoform [12]. TTIp showed a percentage of $100 \%$ inhibition for trypsin.

\section{General Signs of Toxicity}

In this experiment, there were no changes related to the general signs and symptoms of toxicity, such as changes in behavior such as apathy or lack of appetite, changes in response to touch, piloerection or shedding, episodes of diarrhea or constipation and/or death of animals for the groups studied, thus indicating the low toxicity of TTIp in the investigated dose and treatment period.

\section{Liver Enzymes and Histopathological Analysis of the \\ Liver}

Liver enzymes were similar in the studied groups (Table 1). The control group, with animals fed a standard diet, presented livers with better appearance. The main findings were the presence of mild hyperemia, capillary dilation, few foci of mononuclear inflammatory infiltrate in the portal space, and little ballooning degeneration in the periphery of the organ (shown in Fig. 2a). The group that most presented changes in the liver parenchyma, characterizing hepatitis, was the HGLI diet group, composed of animals with obesity fed a high index and glycemic load diet (shown in Fig. 2b). In addition to hyperemia, the changes found in animals with untreated obesity were dilation of capillaries in extensive areas of hepatic paren-
Table 1. Biochemical assessment of liver enzymes in Wistar rats $(n=5)$ after treatment for 10 days

\begin{tabular}{llll}
\hline $\begin{array}{l}\text { Liver enzymes, } \\
\text { mg/dL }\end{array}$ & Groups & & \\
\cline { 2 - 4 } & control & HGLI diet & TTIp \\
\hline GOT & $15.80 \pm 3.35$ & $19.00 \pm 5.34$ & $14.80 \pm 3.56$ \\
GPT & $31.40 \pm 9.56$ & $43.20 \pm 19.20$ & $31.80 \pm 10.78$ \\
GGT & $22.80 \pm 17.11$ & $18.00 \pm 5.10$ & $14.60 \pm 2.07$ \\
\hline
\end{tabular}

Control group: fed a standard diet $\left(\right.$ Labina $\left.{ }^{\circledR}\right)$ throughout the experiment; HGLI diet group: fed a mixture composed of Labina ${ }^{\circledR}$, condensed milk, and sugar (1:1:0.21) throughout the experiment; TTIp group: fed with HGLI diet and treated with TTIp for 10 days of the experiment. GOT, oxalacetic transaminase; GPT, pyruvic glutamic transaminase; GGT, gamma-glutamyl transpeptidase; TTIp, trypsin inhibitor purified from tamarind; HGLI, high glycemic load. The Kruskal-Wallis test and the Dunn post-test were used to evaluate the differences between the groups, $p>0.05$.

chyma of some animals, subcapsular ballooning degeneration band, and scarce and focal areas of necrosis. The TTIp group, with obese animals treated with the inhibitor, presented hyperemia, ballooning degeneration in the peripheral portion of the liver, few areas suggestive of necrosis in 2 slides, dilation of capillaries, and mononuclear infiltrate in another slide (shown in Fig. 2c).

\section{Histopathological Analysis of the Pancreas}

The histopathological analysis of the pancreas showed that in the control group, the eutrophic animals presented normal exocrine and endocrine portions, with some slides showing points of mild hyperemia and a finding of ductal ectasia. Few focal areas of fibrosis and focal islet hyperplasia were also observed (shown in Fig. 3a). The group of untreated animals with obesity (HGLI diet) presented, in general, hyperemia and focal acinar destruction, with replacement of part of the exocrine parenchyma, in line with pancreatitis, observed in mild and moderate degrees. This group also presented mild adipose tissue substitution and pancreatic islet hyperplasia (shown in Fig. 3b). The pancreas layers of animals with obesity that received the inhibitor (TTIp group) showed changes compatible with pancreatitis, with adipose replacement, and mild fibrosis. One of the animals also presented moderate fibrosis. The main histopathological findings in this group were the presence of a few intralobular fibrosis and fat replacement areas on the periphery of the exocrine parenchyma (shown in Fig. 3c). 

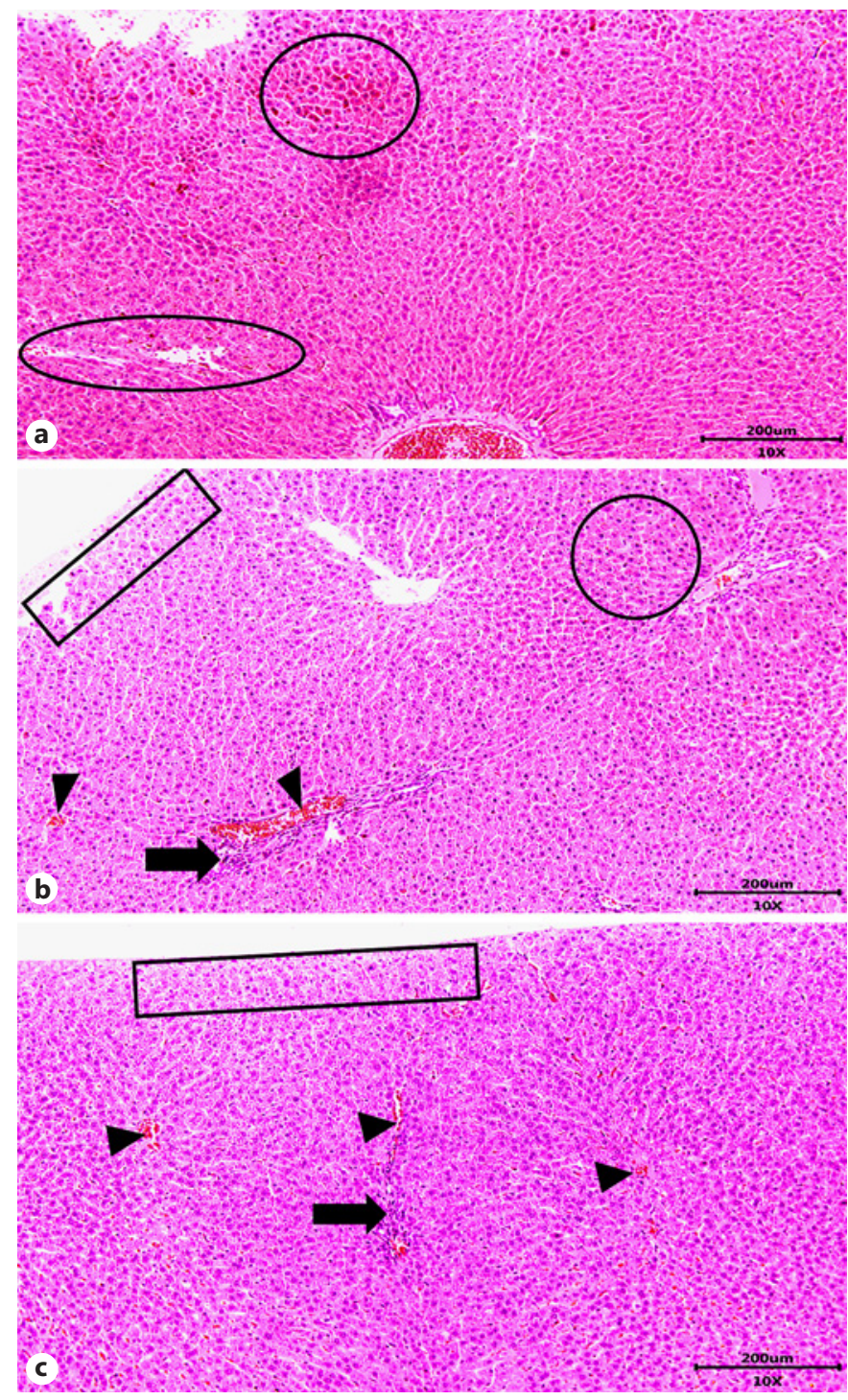

Fig. 2. Histopathological analysis of the livers of Wistar rats $(n=$ 5) after treatment for 10 days. Control group, fed a standard diet (Labina ${ }^{\circledR}$ ) throughout the experiment (a); HGLI group, fed with a mixture composed of Labina ${ }^{\circledR}$, condensed milk, and sugar (1:1:0.21) throughout the experiment (b); TTIp group, fed with HGLI diet and treated with TTIp for 10 days of the experiment (c). Legend: focus of mononuclear inflammatory infiltrate (arrow); necrosis (circle); ballooning degeneration area (rectangle); hyperemia (black arrowhead); dilated capillaries (oval). Scale bars: 200 $\mu \mathrm{m}$. Magnification: $\times 10$. TTIp, trypsin inhibitor purified from tamarind; HGLI, high glycemic load.

Total Volume of the Liver, Pancreas, and Islets

Stereological analysis of the total volume for the liver (shown in Fig. 4a), pancreas (shown in Fig. 4b), and pancreatic islets (shown in Fig. 4c) did not show significant differences between the groups.

Safety and Anti-Inflammatory Effect of Tamarind Multifunctional Protein
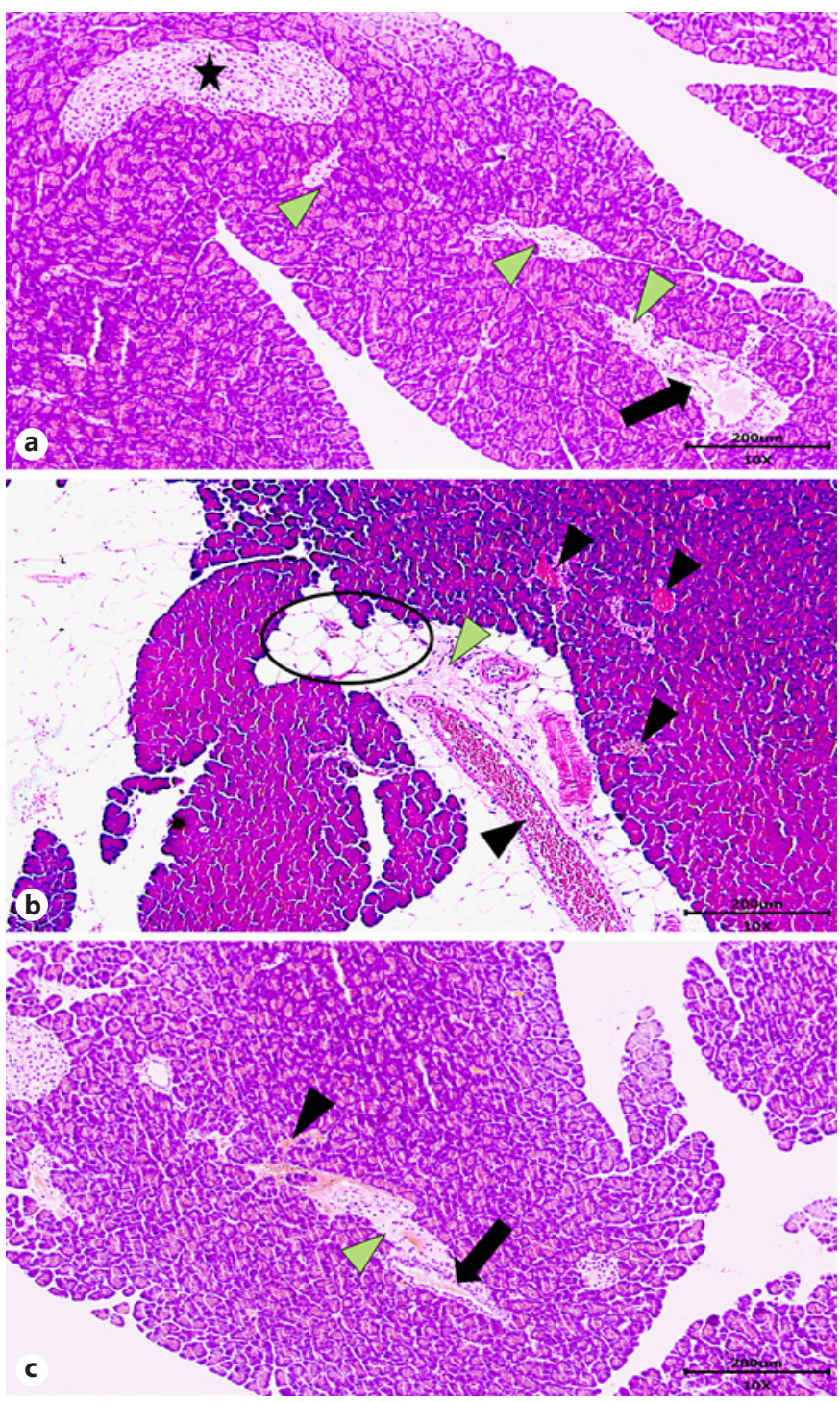

Fig. 3. Histopathological analysis of the pancreas of Wistar rats $(n=5)$ after treatment for 10 days. Control group, fed a standard diet $\left(\right.$ Labina $^{\circledR}$ ) throughout the experiment (a); HGLI group, fed with a mixture composed of Labina ${ }^{\circledR}$, condensed milk, and sugar (1:1:0.21) throughout the experiment (b); TTIp group, fed with HGLI diet and treated with TTIp for 10 days of the experiment (c). Legend: ductal ectasia (arrow); hyperplasia of the pancreatic islet (star); area of replacement of part of the serous acini by unilocular adipocytes (oval); fibrosis (green arrowhead); hyperemia (black arrowhead). Scale bars: $200 \mu \mathrm{m}$. Magnification: $\times 10$. TTIp, trypsin inhibitor purified from tamarind; HGLI, high glycemic load.

\section{Histopathological Analysis of the Small Intestine}

The group of eutrophic animals (control) was the only group that presented the intestine with an area of intact villi (shown in Fig. 5a). The animals in the group with obesity and without treatment (HGLI diet) presented in-

Obes Facts 2021;14:357-369 


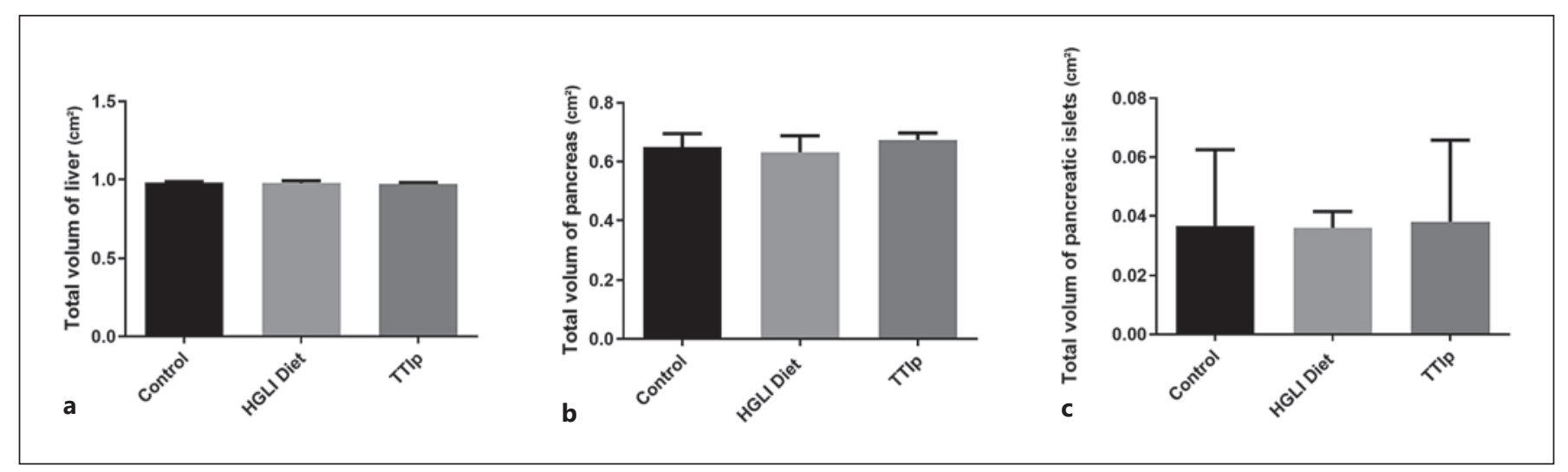

Fig. 4. Total volume of the liver (a), pancreas (b), and pancreatic islets (c) of Wistar rats $(n=5)$ after treatment for 10 days. Control group, fed with standard diet (Labina $\left.{ }^{\circledR}\right)$ throughout the experiment; HGLI Group, fed with a mixture composed of Labina ${ }^{\circledR}$, condensed milk, and sugar (1:1:0.21) throughout the experiment;
TTIp Group, fed with HGLI diet and treated with TTIp for 10 days of the experiment. ANOVA and Tukey's post hoc test were used to assess the differences between the groups, $p>0.05$. TTIp, trypsin inhibitor purified from tamarind; HGLI, high glycemic load. testinal villi with ulcerated areas, some with destroyed villi and areas of necrosis (shown in Fig. 5b). The group of animals with obesity that received the inhibitor (TTIp group) presented villi with fewer ulcerated areas and necrosis. In addition, the presence of foci of mononuclear inflammatory infiltrate located in the lamina propria, however showing other intact layers, was observed in the TTIp group (shown in Fig. 5c).

The semiquantitative analysis showed no significant differences between the groups regarding the percentage parameters of ulcerated villi, the percentage of absent villi, and the percentage of intact intestinal glands (shown in Fig. 6b, c, e). Regarding villus integrity, the group of eutrophic animals (control) and the group of animals with obesity and without treatment (HGLI diet) showed significant differences $(p=0.004)$, while the group with obesity treated with the inhibitor did not differ statistically from these (shown in Fig. 6a). A similar result was observed in the analysis of necrotic villi's presence, with differences between the control and the HGLI diet group $(p=0.000)$, with no differences between these and the TTIp group (shown in Fig. 6d).

The villus length analysis showed that treatment with TTIp positively affected this measure so that the result of this treatment did not differ statistically from the control group. Significant differences were observed between the control $(3,090.5 \pm 189.4)$ and the HGLI diet group $(2,277.5 \pm 247.8)(p=0.003)$ and the HGLI diet group and the TTIp group $(2,899.2 \pm 353.7)$ $(p=0.026)$ (shown in Fig. 7a). Regarding the goblet cell count in the groups' histological slides, no significant differences were observed between them (shown in Fig. 7b).

Total Volume, Volume Density, and Average Sectional Area of Adipocytes

The analysis of the total volume of adipocytes showed significant differences between the means of the group of eutrophic animals (control) $(0.68 \pm 0.06)$ and the group of animals with obesity without treatment (HGLI diet) $(2.10 \pm 1,29)(p=0.047)$ (shown in Fig. 8a). The adipocyte volume density analysis showed no significant differences between the groups (shown in Fig. 8b). The analysis of the average sectional area of adipocytes showed that for the perirenal adipose tissue, significant differences were observed between the control group $(360.0 \pm 63.0)$ and the HGLI diet group $(503.1 \pm 71.8)(p=0.011)$, and between the HGLI diet group and the TTIp group (351.8 \pm $55.5)(p=0.016)$, with no significant differences between the TTIp group and the control group (shown in Fig. 8c).

\section{Histopathological Analysis of Adipose Tissue}

The qualitative analysis of the perirenal visceral adipose tissue showed, in general, similar characteristics between the groups, highlighting the predominance of unilocular adipocytes, few areas of multilocular adipocytes, the presence of lipolysis channels, and hyperemia zones (shown in Fig. 9). The semiquantitative analysis was more sensitive to differences between groups. The analysis of visceral adipose tissue showed no significant differences between groups for the investigation of unilocular adipocytes. All slides presented a score of 4 relative to the pres- 


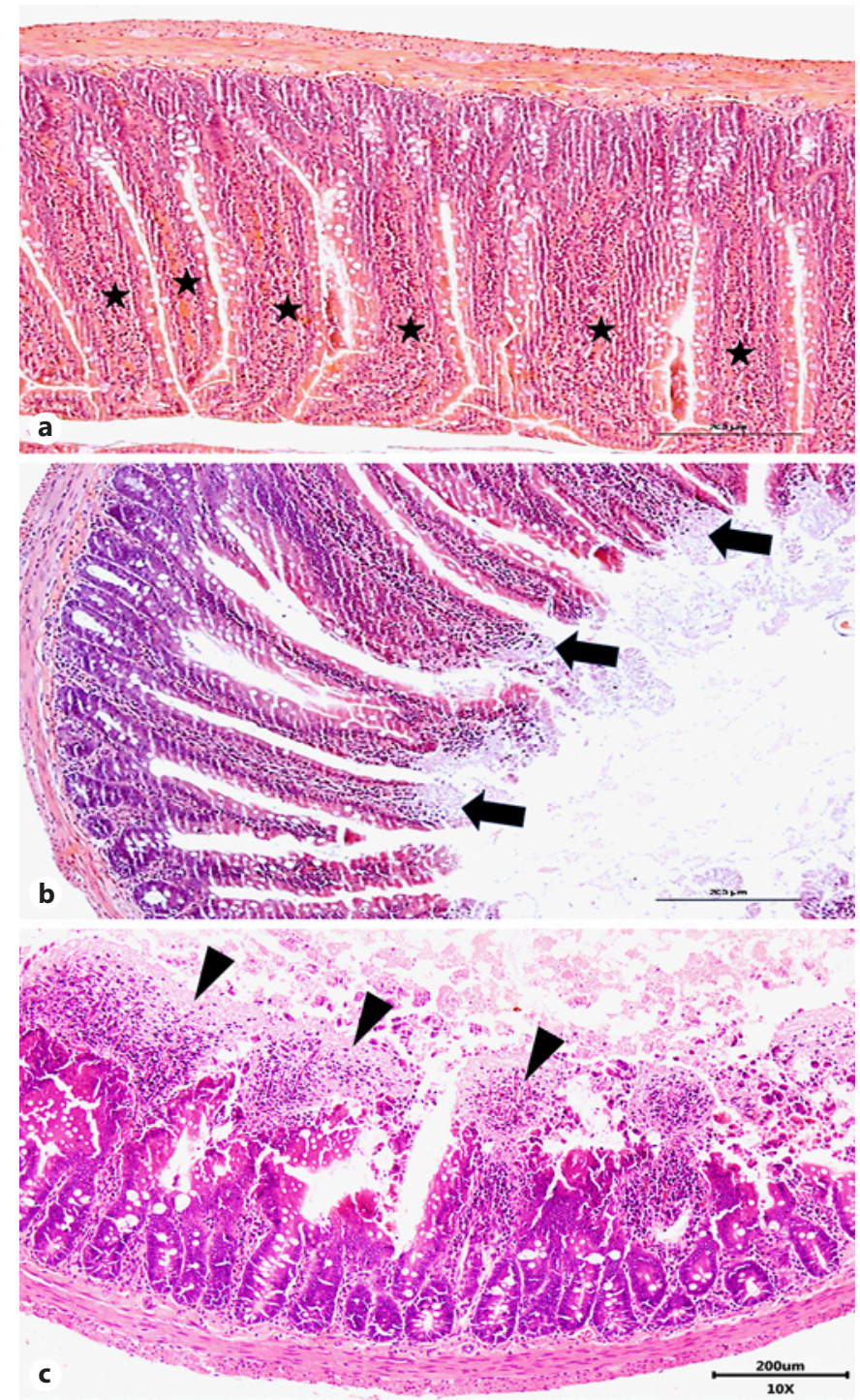

Fig. 5. Histopathological analysis of the small intestine of Wistar rats $(n=5)$ after treatment for 10 days. Control group, fed a standard diet (Labina ${ }^{\circledR}$ ) throughout the experiment (a); HGLI group, fed with a mixture composed of Labina ${ }^{\circledR}$, condensed milk, and sugar (1:1:0.21) throughout the experiment (b); TTIp group, fed with HGLI diet and treated with TTIp for 10 days of the experiment (c). Legend: intact intestinal villi (star); villous ulcer areas (arrows); ulcerated and necrotic villi (black arrowhead). Scale bars: $200 \mu \mathrm{m}$. Magnification: $\times 10$. TTIp, trypsin inhibitor purified from tamarind; HGLI, high glycemic load.

ence of this characteristic in $75-100 \%$ of the analyzed slide (shown in Fig. 10a). The presence of multilocular adipocytes was detected in all groups in a similar percentage, $<25 \%$ (shown in Fig. 10b). A higher percentage of lipolysis was observed in groups whose condition of obe- sity was induced with the use of the HGLI diet compared to eutrophic animals (control), with a significant difference between the control and TTIp groups $(p=0.037)$ (shown in Fig. 10c). The presence of mild inflammatory infiltrates (referring to 3 foci per field) was detected in the control group and the HGLI diet group. In the TTIp group, the presence of these infiltrates was not detected (shown in Fig. 10d). The presence of fibrosis was detected only in the TTIp group (shown in Fig. 10e).

\section{Discussion/Conclusion}

In this study, TTIp was safe and had a potential antiinflammatory effect. The process of obtaining the inhibitor showed a chromatographic profile corresponding to that obtained in the study by Medeiros et al. [12], confirming the purification and anti-trypsin activity by the trypsin inhibition assay. The safety claim is justified by the absence of significant damage to the liver, pancreatic tissue, better appearance in the intestinal villi, and reduced inflammatory evidence in perirenal adipose tissue.

The isolated TTI has been widely studied, not only in terms of its bioactive functions but also in terms of its ability to generate harmful effects. Ribeiro et al. [9] observed that the administration of $25 \mathrm{mg} / \mathrm{kg}$ of TTI did not cause changes in Wistar rats' liver enzymes and serum proteins and did not affect the liver, stomach, intestine, and pancreas histological aspects. TTI did not cause classical deleterious effects on protein digestion and, consequently, malnutrition at doses of $25 \mathrm{mg} / \mathrm{kg}$ and $50 \mathrm{mg} / \mathrm{kg}$, as demonstrated by serum proteins' measurement. However, the purification process can enhance the functional properties of a molecule, making it necessary to reassess the safety of its use.

After purification, TTIp was reassessed for its biological effects. Studies have shown that the purified inhibitor has biological effects when using $730 \mu \mathrm{g} / \mathrm{kg}[12,13]$. At a dose approximately thirty times lower, TTIp performed the same biological activities as TTI. This similar activity emphasized the need to assess whether the use of TTIp generated harmful effects on specific tissues. In the present study, we evaluated potential TTIp sites of action that had not been studied yet: the liver, a classic target tissue in toxicity studies; the pancreas, a classically affected organ by trypsin inhibitors; the adipose tissue, where TTIp had shown anti-inflammatory effects [13], and the intestine.

Although other toxicity study protocols pre-establish the duration of the follow-up and the dose used, this study 

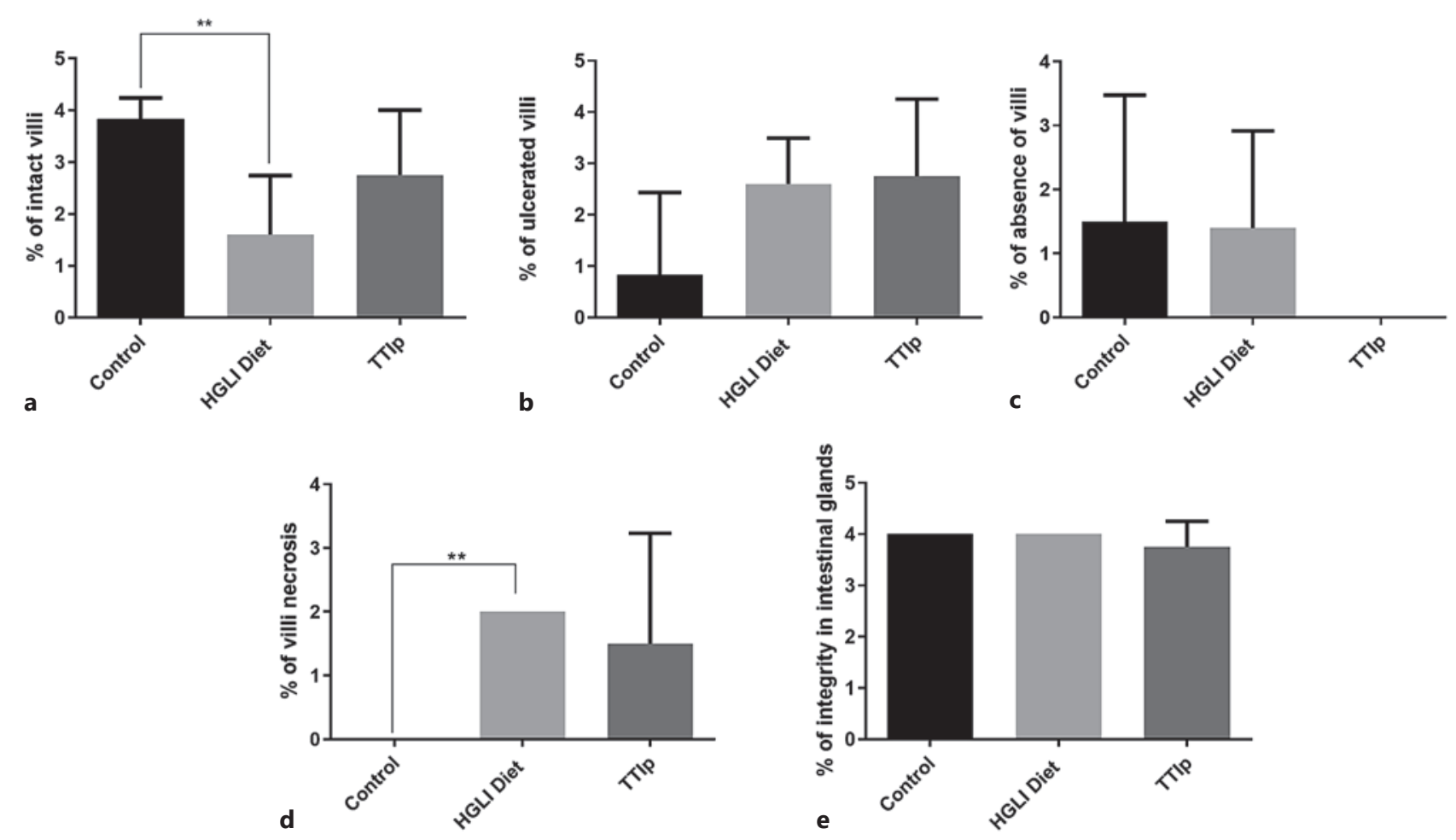

Fig. 6. Semiquantitative analysis of the small intestine of Wistar rats $(n=5)$ after treatment for 10 days. Control group, fed with standard diet (Labina ${ }^{\circledR}$ ) throughout the experiment; HGLI Group, fed with a mixture composed of Labina ${ }^{\circledR}$, condensed milk, and sugar (1:1:0.21) throughout the experiment; TTIp group, fed with HGLI diet and treated with TTIp for 10 days of the experiment.
Percentage of intact villi (a); percentage of ulcerated villi (b); percentage of absence of villi (c); percentage of villi necrosis (d); percentage of integrity in intestinal glands (e). The Kruskal-Wallis test and Dunn's post hoc test were used to assess the differences between the groups, ${ }^{*} p<0.5$. TTIp, trypsin inhibitor purified from tamarind; HGLI, high glycemic load.

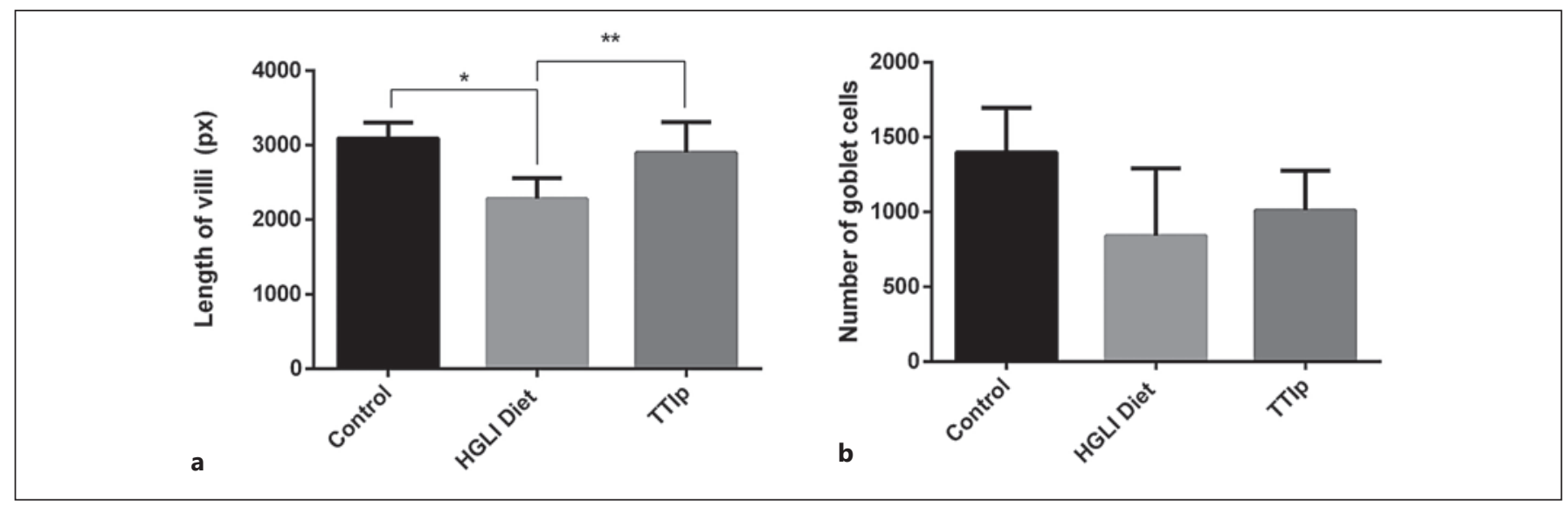

Fig. 7. Histopathological analysis of the small intestine of Wistar rats $(n=5)$ after treatment for 10 days. Control group, fed with standard diet (Labina ${ }^{\circledR}$ ) throughout the experiment; HGLI Group, fed with a mixture composed of Labina ${ }^{\circledR}$, condensed milk, and sugar (1:1:0.21) throughout the experiment; TTIp group, fed with
HGLI diet and treated with TTIp for 10 days of the experiment. a Length of villi and (b) number of goblet cells. ANOVA and Tukey's post hoc test were used to assess the differences between the groups, ${ }^{*} p<0.5$. TTIp, trypsin inhibitor purified from tamarind; HGLI, high glycemic load. 


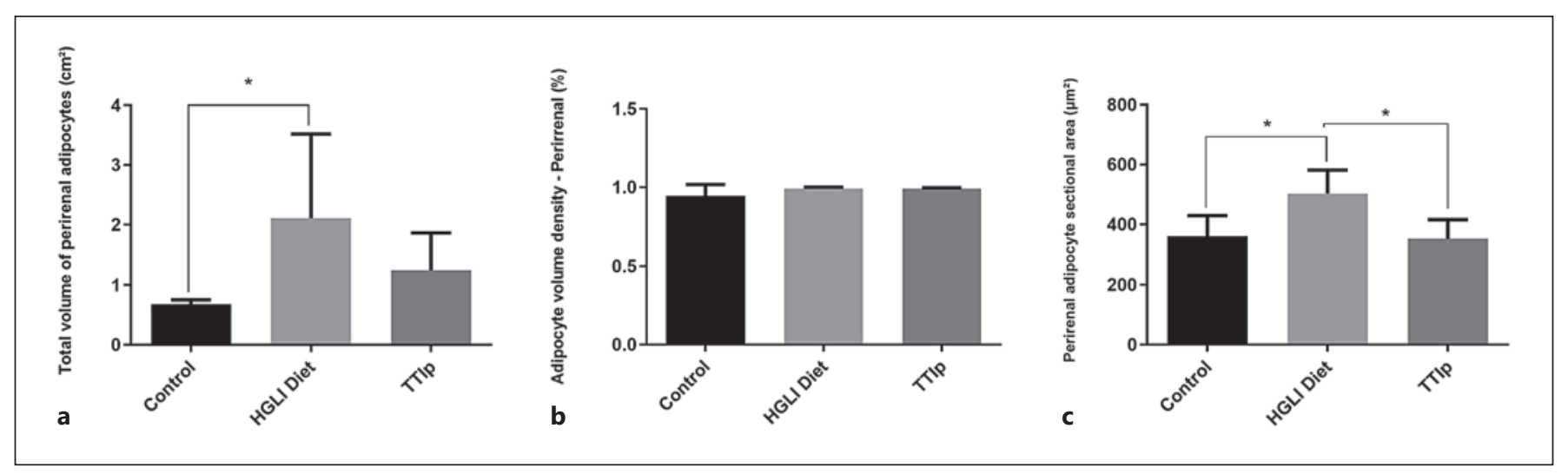

Fig. 8. Total volume (a), volume density (b), and average sectional area (c) of perirenal visceral adipocyte tissue from Wistar rats $(n=5)$ after treatment for 10 days. Control group, fed with standard diet $\left(\right.$ Labina ${ }^{\circledR}$ ) throughout the experiment; HGLI Group, fed with a mixture composed of Labina ${ }^{\circledR}$, condensed milk, and sugar
(1:1:0.21) throughout the experiment; TTIp group, fed with HGLI diet and treated with TTIp for 10 days of the experiment. ANOVA and Tukey's post hoc test were used to assess the differences between the groups, ${ }^{*} p<0.5$. TTIp, trypsin inhibitor purified from tamarind; HGLI, high glycemic load. aimed to evaluate the safety of TTIp using time and a dose consistent with its biological activity. Moreover, the time of use of TTIp is in line with some other studies focusing on the toxicity of other bioactive molecules [24]. Other effects that could be considered in toxicity studies, such as behavioral changes and animals' death, were not detected when TTIp was administered.

The liver is one of the best markers of physiological and pathological status in human and animal studies. The group of animals with obesity treated with TTIp, compared to the control group, composed of untreated eutrophic animals, did not present critical hepatic alterations, either in the histopathological analysis or in the total volume of hepatocytes. These results are reinforced by the absence of changes in liver enzymes when compared to the control. Similar changes, such as necrosis and pycnosis and the presence of mild signs of inflammation, were observed in a study with Wistar rats fed with protein hydrolysates from the microalgae Bellerochea malleus and were considered less important [25].

The pancreas is an organ classically involved in the metabolism of serine protease inhibitors. There are comprehensive reports in the literature on the deleterious effects of these proteins in this tissue, especially cellular hypertrophy $[16,26]$. The TTIp group presented pancreatic parenchyma similar to the group of animals that did not receive treatment. Additionally, the stereological analysis did not differ between the groups, nor for acinar parenchyma, nor specifically for islets. Luz et al. [17] evaluated the effect of HGLI in the pancreas of Wistar rats. They observed interlobular accumulation of adipocytes in the parenchyma of animals fed this experimental diet. Thus, these changes may be due to the obesity induced by diet because the findings were similar in these groups. Fibrosis was a common finding among the 3 groups of Wistar rats, including the control group.

Obesity is closely related to the loss of competence of the intestinal barrier, an important pathophysiological mechanism of the mucosa's inflammatory process. TNF- $\alpha$ is a cytokine that triggers pro-inflammatory signaling in intestinal epithelial cells, inducing marked increases in intestinal permeability regardless of these cells death [27].

The intestine's semiquantitative analysis showed that for percentage of intact villi, ulcerated villi, villus absence, villus necrosis, percentage of intestinal gland integrity and goblet cell count, no significant differences were observed between groups, showing that TTIp did not bring any additional deleterious effects to this tissue. In contrast, the villus length analysis showed that the TTIp group and the control group (eutrophic) differed from the group with untreated obesity (HGLI diet), showing that in addition to not causing damage, the molecule may have generated an additional regenerating effect. Despite the absence of statistical significance regarding semiquantitative analysis, the means of these analyses seem to correspond to the qualitative analysis of the intestinal epithelium.

Intestinal growth and an increase in the crypt imply an increase in intestinal epithelial cells and greater absorption. Reducing the mucosal area can result in damage to intesti- 


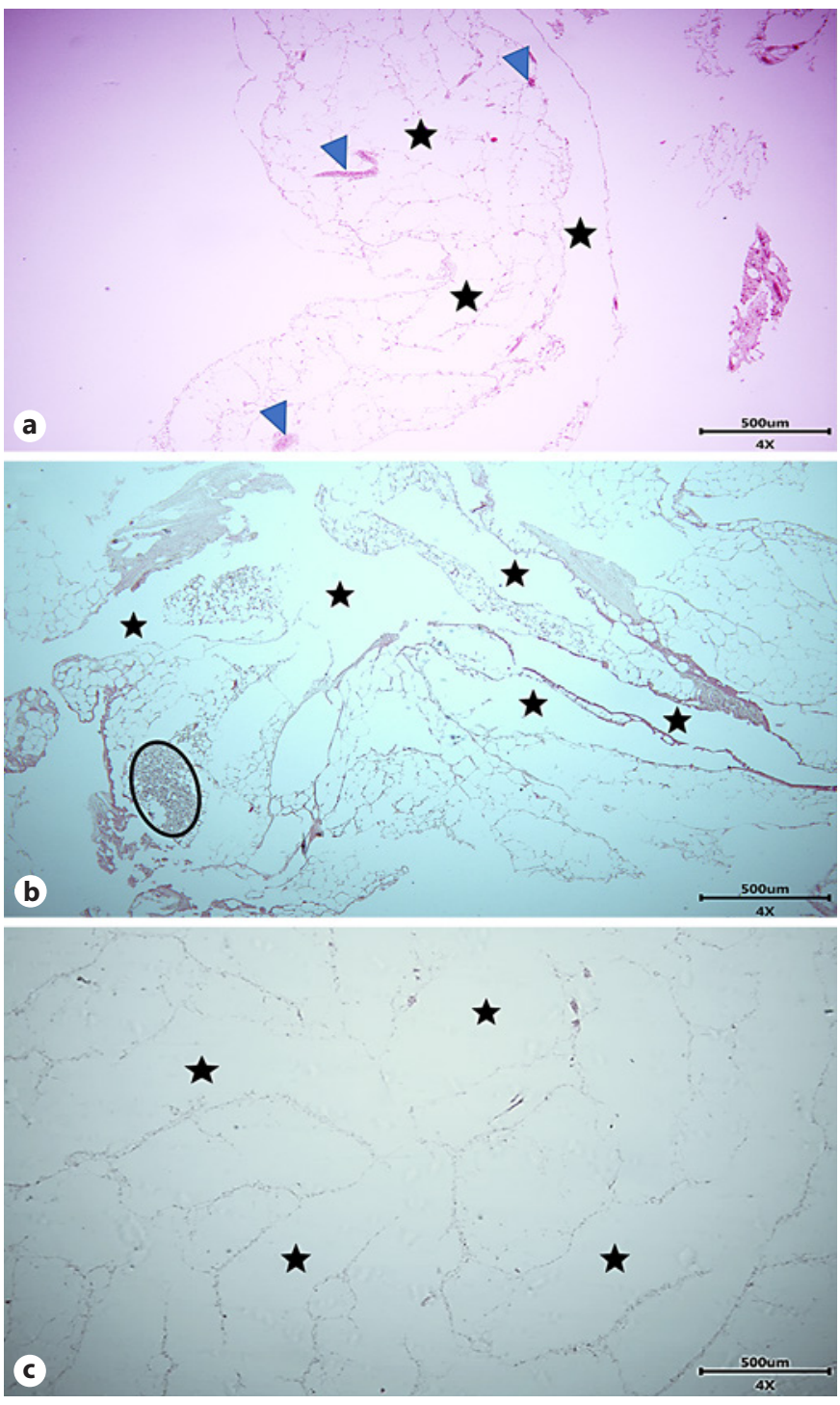

Fig. 9. Histopathological analysis of perirenal adipose tissue from Wistar rats $(n=5)$ after treatment for 10 days. Control group, fed with standard diet $\left(\right.$ Labina $\left.{ }^{\circledR}\right)$ throughout the experiment (a); HGLI Group, fed with a mixture composed of Labina ${ }^{\circledR}$, condensed milk, and sugar (1:1:0.21) throughout the experiment (b); TTIp group, fed with HGLI diet and treated with TTIp for 10 days of the experiment (c). Legend: lipolysis channels (star); multilocular adipocytes (oval); hyperemia (blue arrowhead). Scale bars: $200 \mu \mathrm{m}$. Magnification: $\times 4$. TTIp, trypsin inhibitor purified from tamarind; HGLI, high glycemic load.

nal absorption [28]. The obesity-inducing diet, also used in the group treated with TTIp, is a potent inducer of mucosal architecture disorganization, with a visible reduction in intestinal villi, as observed in the previous study by Luz et al. [17], which evaluated the effects of an HGLI diet.
The obesity model was included in this study because it is the metabolic condition in which TTIp has been extensively studied. In obesity, individual adipocytes and white adipose tissue's morphology and function are altered, leading to a remodeling process. When a chronic positive energy balance occurs, adipocytes store excess energy as triacylglycerols, expanding in size (hypertrophy) and number (hyperplasia) [29].

The total volume, volume density, and average sectional area of adipocytes are indicators of the process of hypertrophy and cellular hyperplasia. In this study, the alteration of some of these parameters compared to the eutrophic control was expected due to the HGLI diet. Other studies also reported increased visceral adipose tissue and cell size in response to the consumption of a highcalorie diet [30, 31].

However, in a previous study in which the performance of TTIp was assessed for weight loss in animals with obesity, weight changes were not considered significant, despite a reduction in food consumption [13]. Weight loss in a toxicity experiment is an indicator of damage caused by the evaluated molecule or substance, with the magnitude of the loss being as great as the exposure [32]. Weightlessness observed by Carvalho et al. [13] can be considered an indicator of the low toxicity of TTIp.

Body composition and regional fat deposition, particularly visceral fat accumulation, are essential mediators in obesity and its related comorbidities. They are related to increased secretion of inflammatory adipokines/cytokines and acute phase proteins and decreased adipokines/ anti-inflammatory cytokines [31].

Perirenal visceral adipose tissue was analyzed due to recent discoveries about the role of TTIp in inflammatory parameters in this tissue. Carvalho et al. [13], working with the same experimental model, observed that plasma concentrations and TNF- $\alpha$ mRNA expression in perirenal visceral adipose tissue were reduced in animals with obesity treated with TTIp. In addition to this reduction, TTIp led to an improvement in the lipid profile. These reductions occurred independently of weight loss and were possibly induced by satiety.

According to Carvalho et al. [13], the histopathological analysis of the perirenal adipose tissue demonstrated an absence of inflammatory infiltrates in the analyzed slides. The expansion of adipose tissue in obesity is linked to an inadequate supply of oxygen and hypoxia development. The growth of adipose tissue is limited, and excess triglycerides are stored in ectopic tissues. Stressed adipocytes and hypoxia contribute to the immigration and activation of immune cells [33]. Immune cells infiltrating 


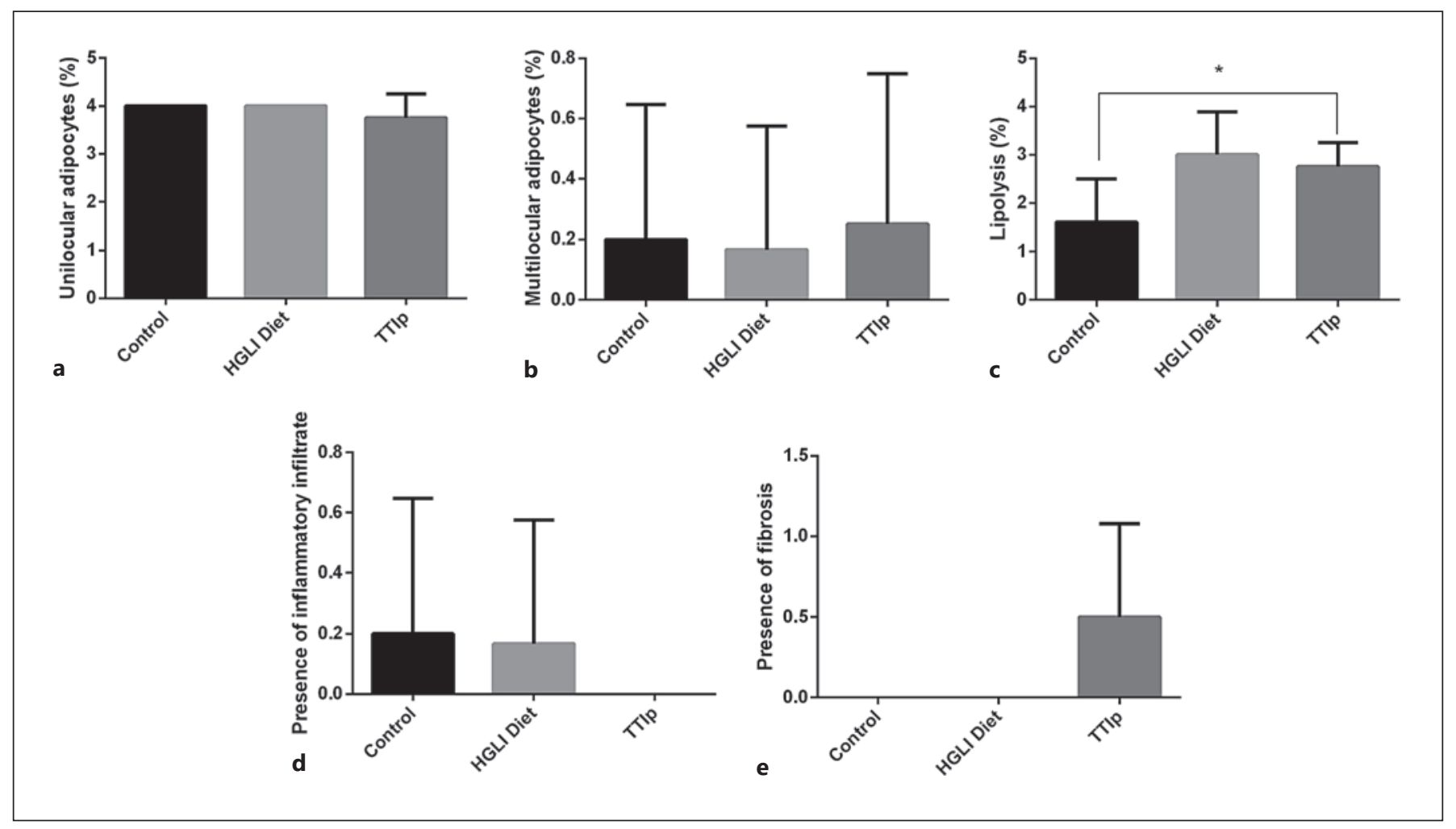

Fig. 10. Semiquantitative analysis of perirenal adipose tissue from Wistar rats $(n=5)$ after treatment for 10 days. Control group, fed with standard diet $\left(\right.$ Labina $\left.{ }^{\circledR}\right)$ throughout the experiment; HGLI Group, fed with a mixture composed of Labina ${ }^{\circledR}$, condensed milk, and sugar (1:1:0.21) throughout the experiment; TTIp group, fed with HGLI diet and treated with TTIp for 10 days of the experi-

the adipose tissue contribute extensively to the production and secretion of the same inflammatory mediators and promote the systemic inflammatory state. TNF- $\alpha$ is one of the leading promoters of this event [34].

However, fibrosis was observed only in the adipose tissue of animals treated with TTIp. Adipose tissue fibrosis has multiple potential effects on adipocytes. By providing a rigid extracellular matrix, fibrosis can prevent excessive adipocyte growth. Fibrosis can exert shear stress on the adipocyte membrane, opposing the mechanical stress exerted by increased lipid droplets within the cell. Adipose tissue fibrosis can also activate signaling events secondary to extracellular matrix ligands at receptors on the cell surface that bind to fibrotic tissue. It is debatable whether adipose tissue fibrosis is beneficial for metabolic homeostasis, with studies supporting both possibilities [35].

The histopathological analysis also showed the predominance of unilocular adipocytes, with large lipid droplets, characteristics of the white adipose tissue, and ment. Percentage of unilocular adipocytes (a); percentage of multilocular adipocytes (b); percentage of lipolysis (c); presence of an inflammatory infiltrate (d); presence of fibrosis (e). ANOVA and Tukey's post hoc test were used to assess the differences between the groups, ${ }^{*} p<0.5$. TTIp, trypsin inhibitor purified from tamarind; HGLI, high glycemic load. low concentration of multilocular adipocytes, with cytoplasm containing numerous and smaller lipid droplets, typical of brown adipose tissue, in all groups. Lipolysis was more present in the groups in which obesity was induced, possibly resulting from adipose tissue expansion.

The adipose tissue findings were consistent with the antiinflammatory action of TTIp in another study [13]; in addition to its protective effect on the small intestine mucosa, its biological activity is still unknown. Such findings lead to the belief that in addition to the potent anti-inflammatory activity confirmed in adipocytes and revealed in the intestine in the present study, it is safe to use TTIp as an adjuvant in the treatment of metabolic and inflammatory diseases.

In conclusion, the purified trypsin inhibitor of tamarind in its bioactive dose did not cause signs or symptoms of general toxicity and damage to the liver and pancreatic tissue of obese Wistar rats. In addition to these effects, TTIp promoted a protective effect on these animals' intestine, reducing the loss of intestinal villi, a damage that is already well char- 
acterized in obesity models with chronic inflammation. TTIp also reduced the presence of inflammatory infiltrates in perirenal adipose tissue. Therefore, its use in the studied models is potentially safe and desirable, considering its antiinflammatory effect. In future studies, TTIp might be evaluated as adjuvant therapy for obesity or other conditions involving the development of an inflammatory response.

\section{Acknowledgement}

The authors thank the Federal University of Rio Grande do Norte (UFRN), especially the Pro-Rectory of Postgraduate and the Pro-Rectory of Research, for all efforts dedicated to supporting our institution's research.

\section{Statement of Ethics}

All experiments were developed according to the Guide for the Care and Use of Laboratory Animals (2011) and approved by the Ethics Committee on the Use of Animals (CEUA-UnP), protocol No. 012/2015.

\section{Conflict of Interest Statement}

The authors have no conflicts of interest to declare.

\section{Funding Sources}

This work was supported by the Coordenação de Aperfeiçoamento de Pessoal de Nível Superior (Finance Code 001-CAPES) and the Conselho Nacional de Desenvolvimento Cientítico e Tecnológico (Award Number: 426116/2018-6-CNPq).

\section{Author Contributions}

Vanessa C.O. Lima, Anna B.S. Luz, Fabiana M.C. Carvalho, and Julia B.S. Figueredo collaborated with the extraction, isolation, and purification of the tamarind trypsin inhibitor. Vanessa C.O. Lima, Anna B.S. Luz, Maíra C.J.S. Lima, Fabiana M.C. Carvalho, and Julia B.S. Figueredo collaborated with the application of the inhibitor in an experimental model and extraction of biological material. Anna B.S. Luz, Maria do Socorro M. Amarante, Julia B.S. Figueredo, and Christina S. Camillo collaborated with the processing of biological materials and the preparation of histological slides. Vanessa C.O. Lima, Anna B.S. Luz, Pedro P.A. Santos, Christina S. Camillo, and Fernando V.L. Ladd collaborated with image capture and analysis of histological slides. Vanessa C.O. Lima and Anna B.S. Luz collaborated with data tabulation and statistical analysis. Vanessa C.O. Lima, Bruna L.L. Maciel, Adriana F. Uchôa, and Ana H.A. Morais collaborated with the writing and revision of this manuscript. All authors involved in the preparation of this manuscript approved the final version.

\section{References}

1 World Health Organization [internet]. Global Health Observatory (GHO) data. Overweight and obesity. [cited 2020 May 16]. Available from: https://www.who.int/newsroom/fact-sheets/detail/obesity-and-overweight.

2 Afshin A, Forouzanfar MH, Reitsma MB, Sur P, Estep K, Lee A, et al. The GBD 2015 obesity collaborators. Health effects of overweight and obesity in 195 countries over 25 years. N Engl J Med. 2017 Jul;377(1):13-27.

3 Srivastava G, Apovian C. Future pharmacotherapy for obesity: new anti-obesity drugs on the horizon. Curr Obes Rep. 2018 Mar;7(2): $147-61$.

4 Hooper NM, Lendeckel U. Proteases in tissue remodeling of lung and heart. Kluwer Academic/Plenum Publishers; 2003. Vol. 1; p. 139-55.

5 Qi RF, Song ZW, Chi CW. Structural features and molecular evolution of bowman-birk protease inhibitors and their potential application. Acta Biochim Biophys Sin. 2005 May; 37(5):283-92.

6 Clemente A, Moreno FJ, Marín-Manzano MDC, Jiménez E, Domoney C. The cytotoxic effect of Bowman-Birk isoinhibitors, IBB1 and IBBD2, from soybean (Glycine max) on
HT29 human colorectal cancer cells is related to their intrinsic ability to inhibit serine proteases. Mol Nutr Food Res. 2010 Mar;54(3): 396-405.

7 Lima VCO, Machado RJA, Monteiro NKV, Lyra IL, Camillo CS, Serquiz AC, et al. Gastroprotective and antielastase effects of protein inhibitors from Erythrina velutina seeds in an experimental ulcer model. Biochem Cell Biol. 2016 Apr;95(2):243-50.

8 Lima VCO, Piuvezam G, Maciel BLL, Morais AHA. Trypsin inhibitors: promising candidate satietogenic proteins as complementary treatment for obesity and metabolic disorders? J Enzyme Inhib Med Chem. 2019 Jan; 34(1):405-19.

9 Ribeiro JA, Serquiz AC, Silva PF, Barbosa PB, Sampaio TB, Araújo Junior RF, et al. Trypsin inhibitor from Tamarindus indica L. seeds reduces weight gain and food consumption and increases plasmatic cholecystokinin levels. Clinics. 2015 Feb;70(2):136-43.

10 Carvalho FM, Lima VC, Costa IS, Medeiros AF, Serquiz AC, Lima MC, et al. A trypsin inhibitor from tamarind reduces food intake and improves inflammatory status in rats with metabolic syndrome regardless of weight loss. Nutrients. 2016 Oct;8(10):544.
11 Costa IS, Medeiros AF, Carvalho FMC, Lima VCO, Serquiz RP, Serquiz AC, et al. Satietogenic protein from tamarind seeds decreases food intake, leptin plasma and CCK-1r gene expression in obese wistar rats. Obes Facts. 2018 Dec;11(6):440-53.

12 Medeiros AF, Costa IS, Carvalho FMC, Kiyota K, Souza BBP, Sifuentes DN, et al. Biochemical characterization of a Kunitz-type inhibitor from Tamarindus indica L. seeds and its efficacy in reducing plasma leptin in an experimental model of obesity. J Enzyme Inhib Med Chem. 2018 Jan;33(1):334-48.

13 Carvalho FMC, Lima VCO, Costa IS, Luz ABS, Ladd FVL, Serquiz AC, et al. AntiTNF- $\alpha$ agent tamarind kunitz trypsin inhibitor improves lipid profile of wistar rats presenting dyslipidemia and diet-induced obesity regardless of PPAR- $\gamma$ induction. Nutrients. 2019 Mar;11(3):512.

14 Winer DA, Luck H, Tsai S, Winer S. The intestinal immune system in obesity and insulin resistance. Cell Metab. 2016 Mar;23(3):413-26.

15 Maurizi G, Della Guardia L, Maurizi A, Poloni A. Adipocytes properties and crosstalk with immune system in obesity-related inflammation. J Cell Physiol. 2017 Feb;233(1): 88-97. 
16 Samtiya M, Aluko RE, Dhewa T. Plant food anti-nutritional factors and their reduction strategies: an overview. Food Prod Process and Nutr. 2020 Mar;2(1):1-14.

17 Luz ABS, Dos Santos Figueredo JB, Salviano BDPD, Aguiar AJFC, Pinheiro LGSD, Krause MFD, et al. Adipocytes and intestinal epithelium dysfunctions linking obesity to inflammation induced by high glycemic index pellet-diet in Wistar rats. Biosci Rep. 2018 Jun 27; 38(3):BSR20180304.

18 Kakade ML, Simons NR, Liener IE. An evaluation of natural versus synthetic substrates for measuring the antitrytic activity of soybean samples. Cereal Chem. 1969 Sep;46(5):51826.

19 Silva PF, McGurk C, Knudsen DL, Adams A, Thompson KD, Bron JE. Histological evaluation of soya bean-induced enteritis in Atlantic salmon (Salmo salar L.): quantitative image analysis versus semi-quantitative visual scoring. Aquaculture. 2015 Aug;445:42-56.

20 Bombardieri M, Barone F, Pittoni V, Alessandri C, Conigliaro P, Blades MC, et al. Increased circulating levels and salivary gland expression of interleukin-18 in patients with Sjögren's syndrome: relationship with autoantibody production and lymphoid organization of the periductal inflammatory infiltrate. Arthritis Res Ther. 2004 Aug;6(5):R447-56.

21 Churg A, Bilawich A. Confluent fibrosis and fibroblast foci in fibrotic non-specific interstitial pneumonia. Histopathology. 2016 Jul; 69(1):128-35.
22 Ribeiro AA, Davis C, Gabella G. Estimate of size and total number of neurons in superior cervical ganglion of rat, capybara and horse. Anat Embryol. 2004 Jul;208(5):367-80.

23 Bargut TC, Souza-Mello V, Mandarim-deLacerda CA, Aguila MB. Fish oil diet modulates epididymal and inguinal adipocyte metabolism in mice. Food Funct. 2016 Mar;7(3): 1468-76.

24 Mehrzadi S, Fatemi I, Esmaeilizadeh M, Ghaznavi H, Kalantar H, Goudarzi M. Hepatoprotective effect of berberine against methotrexate induced liver toxicity in rats. Biomed Pharmacother. 2018 Jan;97:233-9.

25 Barkia I, Ketata Bouaziz H, Sellami Boudawara T, Aleya L, Gargouri AF, Saari N. Acute oral toxicity study on Wistar rats fed microalgal protein hydrolysates from Bellerochea malleus. Environ Sci Pollut Res Int. 2020 Jun;27(16):19087-94.

26 Wedekind KJ, Chen J, Yan F, Escobar J, Vazquez-Anon M. Efficacy of a mono-component protease is affected by trypsin inhibitor concentration in soybean meal. Anim Feed Sci Technol. 2020 Jul;265:114502.

27 Mashukova A, Wald FA, Salas PJ. Tumor necrosis factor alpha and inflammation disrupt the polarity complex in intestinal epithelial cells by a posttranslational mechanism. Mol Cell Biol. 2011 Feb;31(4):756-65.

28 Hermes C, Azevedo JFd., Araújo EJd. A, Sant'Ana Dd. MG. Intestinal ascending colon morphometrics in rats submitted to severe protein malnutrition. Int J Morphol.. 2008 Mar;26(1):5-11.
29 Parlee SD, Lentz SI, Mori H, MacDougald OA. Quantifying size and number of adipocytes in adipose tissue. Met Enzimol. 2014 Jun;537:93-122.

30 Lee KH, Kim NH. Expressional patterns of connexin isoforms in the rat epididymal fat during postnatal development. Dev Reprod. 2018 Mar;22(1):29-38.

31 Poret JM, Souza-Smith F, Marcell SJ, Gaudet DA, Tzeng TH, Braymer HD, et al. High fat diet consumption differentially affects adipose tissue inflammation and adipocyte size in obesity-prone and obesity-resistant rats. Int J Obes (Lond). 2018 Mar;42(3):535-41.

32 Wang M, Guckland A, Murfitt R, Ebeling M, Sprenger D, Foudoulakis M, et al. Relationship between magnitude of body weight effects and exposure duration in mammalian toxicology studies and implications for ecotoxicological risk assessment. Environ Sci Eur. 2019 Jun;31(1):1-7.

33 Datta R, Podolsky MJ, Atabai K. Fatty fibrosis: friend or foe? JCI Insight. 2018 Oct 4;3(19): e122289.

34 Blühe M. Adipose tissue inflammation: a cause or consequence of obesity-related insulin resistance? Clin Sci. 2016 Sep 1;130(18): 1603-14.

35 Haugen F, Drevon CA. The interplay between nutrients and the adipose tissue: plenary lecture. Proc Nutr Soc. 2007 May;66(2):171-82. 